\title{
Locally Advanced Unresectable Esophageal Adenocarcinoma
}

National Cancer Institute

\section{Source}

National Cancer Institute. Locally Advanced Unresectable Esophageal Adenocarcinoma. NCI Thesaurus. Code C162113.

Esophageal adenocarcinoma that has spread from its original site of growth to nearby tissues or lymph nodes and is not amenable to surgical resection. 